struggling to find a middle road between two diametrically opposed approaches to the development of such databases. Top-down pressure by the agency on researchers to use certain software or formats would probablyimpede their development. But a bottom-up strategy that merely encourages cross-project cooperation, while allowing researchers total freedom to devise their own databases, is bound to be chaotic, does not guarantee cross-compatibility of data, and ultimately reduces the likelihood that their contents will be used to maximally benefit research.

What is clear is that individual labs can no longer make much progress alone. Currently, many researchers feel they are drowning in data. For all they know, a database might contain answers to patient safety issues or glimmers of new therapeutics - but this is being lost through an inability to effectively harvest the data already available. Other opportunities are missed because both experts and data are 'silo'-ed in isolated and often inaccessible systems. On top of these issues is the fact that neither databases nor the experts that create them are permanent or inseparable.

The NIH and its equivalent agencies elsewhere in the world are now turning their attention to working out how best to assist the growth of validated and accessible databases. This should involve, at the least, development of policies for evaluating proposals on databases and associated analytic tools, for their sustained funding, and for ensuring that the data deposited remain accessible long after the project originators have moved on.

The NIH itself, if it chose, could aim for something grander. It could take it upon itself to define a broad reference model and the basic architecture for knowledge environments. It could even build a centralized warehouse with Google-like storage, a veritable National Biomedical Resource of raw data and the tools to access and analyse them. The challenge then would be how to store, retrieve and read data created on multiple systems by diverse research groups.

But perhaps it will prove more realistic for the US agency to concentrate on improving the inter-operability of databases, rather than

pushing for their merger, and to provide incentives for building in 'joins' from the start. The NIH should work on this with industrial companies and other government agencies.

All funders should also be aware of the need to support viable career paths for the software engineers and bioinformaticians who create the knowledge environments and curate the data in them. And in order to obtain value for money, it will be vital for funding agencies to carefully select the databases they choose to support and then to support them for the long term.

They must encourage the sustained availability of these data and build incentives for the development of cross-querying capability.

As things stands, even popular databases such as PhysioNet (www. physionet.org), which is facing loss of NIH funding after seven years in development, often lack secure funding. In order to get value, the NIH and

"To obtain value for money, it will bevital for funding agencies tocarefully select the databases they choose to support and then to support them for the long term." other funding agencies need to develop policies for such knowledge environments that will allow long-term support of successful ones.

Researchers also need stronger incentives to sustain their own participation in building knowledge environments. At a minimum, contributors should receive a citable acknowledgement of depositions. Leadership and trust are required to ensure that primary researchers personally benefit from storing their data in open databases.

Michael Huerta, associate director of the National Institute of Mental Health, told those at the Bethesda meeting that the NIH is keen to get more mileage out of high-throughput data acquired with public funds. But that will mean that the agency should require the databases it supports to be equipped with tools and protocols that researchers find convenient to use. Ultimately, these databases must show that their data are being used by other groups, and generating work of publishable quality.

\section{Capitol calling}

\section{A fresh perspective on science and politics.}

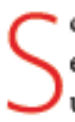
cientists typically master the requirements of their vocation early on - delivering a lecture, writing a grant proposal, setting up a lab. And yet even some of the most accomplished scientists remain largely in the dark about the most basic information underpinning their work: the circumstances surrounding the decision to pay them to do the science in the first place.

The world leader in the public funding of science is, of course, the United States. And America's purse-strings are held not by the president, but by the 435 representatives and 100 senators who make up the US Congress. Many scientists have only the vaguest idea about how that much-maligned institution does its business.

On page 248 of this issue, we introduce a new column that is intended to rectify that and to give readers of Nature a fuller insight into how and why different topics take their place in America's research and development agenda. Until the end of last year, the column's author, David Goldston, served as chief of staff for the House Committee on Science, helping to set the legislative agenda for science and technology before Congress.

For the past 20 years, Goldston has been at the heart of forging US science and environmental policy. He is now leaving Capitol Hill on the retirement of his long-time boss, Representative Sherwood Boehlert (Republican, New York). In addition to writing exclusively for Nature, Goldston will serve as a visiting lecturer in science and environmental policy at the Woodrow Wilson School of Public and International Affairs at Princeton University, New Jersey.

Goldston's column, Party of One, will provide a seasoned insider's take on the interaction between science and politics. From stem cells and energy policy to dimate change and space exploration, it will provide a unique perspective on why things work, or don't work, in Washington DC. And stripped of the congressional staffer's customary anonymity, Goldston will be able to offer his own candid opinions on what's really up, on Capitol Hill. As a result, we are confident that our readers in the United States and around the world will gain a valuable insight into some of the forces that help shape science today. 